\title{
Cardiac Safety of TGF- $\beta$ Receptor I Kinase Inhibitor LY2157299 Monohydrate in Cancer Patients in a First-in-Human Dose Study
}

\author{
Richard J. Kovacs • Giuliana Maldonado • Analia Azaro • Maria S. Fernández • \\ Federico L. Romero $\cdot$ Juan M. Sepulveda-Sánchez $\cdot$ Mary Corretti • \\ Michael Carducci • Melda Dolan · Ivelina Gueorguieva - Ann L. Cleverly • \\ N. Sokalingum Pillay $\cdot$ Jose Baselga $\cdot$ Michael M. Lahn
}

Published online: 9 December 2014

(c) The Author(s) 2014. This article is published with open access at Springerlink.com

\begin{abstract}
Transforming growth factor-beta (TGF- $\beta$ ) signaling plays an important role in the fetal development of cardiovascular organs and in the repair mechanisms of the heart. Hence, inhibitors of the TGF- $\beta$ signaling pathway require a careful identification of a safe therapeutic window and a comprehensive monitoring of the cardiovascular system. Seventy-nine cancer patients (67 glioma and 12 solid tumor) enrolled in a first-in-human dose study and received the TGF- $\beta$ inhibitor LY2157299 monohydrate (LY2157299) as monotherapy ( $n=53)$ or in combination with lomustine $(n=26)$. All patients were monitored using 2D echocardiography/color and Spectral Doppler (2D Echo with Doppler) every 2 months, monthly electrocardiograms, thorax computer tomography scans every 6 months, and monthly serum brain natriuretic peptide (BNP), troponin I, cystatin C, high-sensitivity C-reactive protein (hs-CRP). Administration of LY2157299 was not
\end{abstract}

R. J. Kovacs

Krannert Institute of Cardiology, Indiana University School of Medicine, Indianapolis, IN 46202, USA

e-mail: rikovacs@iupui.edu

G. Maldonado

Department of Cardiology, Vall d'Hebron, Barcelona, Spain

e-mail: giulymaldonado@hotmail.com

\section{A. Azaro · J. Baselga}

Medical Oncology, Vall d'Hebron, Barcelona, Spain

e-mail: a.azaro@vhebron.net

J. Baselga

e-mail: baselgaj@mskcc.org

M. S. Fernández · F. L. Romero

Department of Cardiology, Hospital Universitario 12 de Octubre, Madrid, Spain

e-mail: sfcasares@gmail.com associated with medically relevant cardiovascular toxicities, including patients treated $\geq 6$ months $(n=13)$. There were no increases of troponin I, BNP, or hs-CRP or reduction in cystatin $\mathrm{C}$ levels, which may have been considered as signs of cardiovascular injury. Blood pressure was generally stable during treatment. Imaging with echocardiography/Doppler showed an increase in mitral and tricuspid valve regurgitation by two grades of severity in only one patient with no concurrent clinical symptoms of cardiovascular injury. Overall, this comprehensive cardiovascular monitoring for the TGF- $\beta$ inhibitor LY2157299 did not detect medically relevant cardiac toxicity and hence supports the evaluation of LY2157299 in future clinical trials.

Keywords LY2157299 - Cardiac safety · Glioma · First-in-human dose study

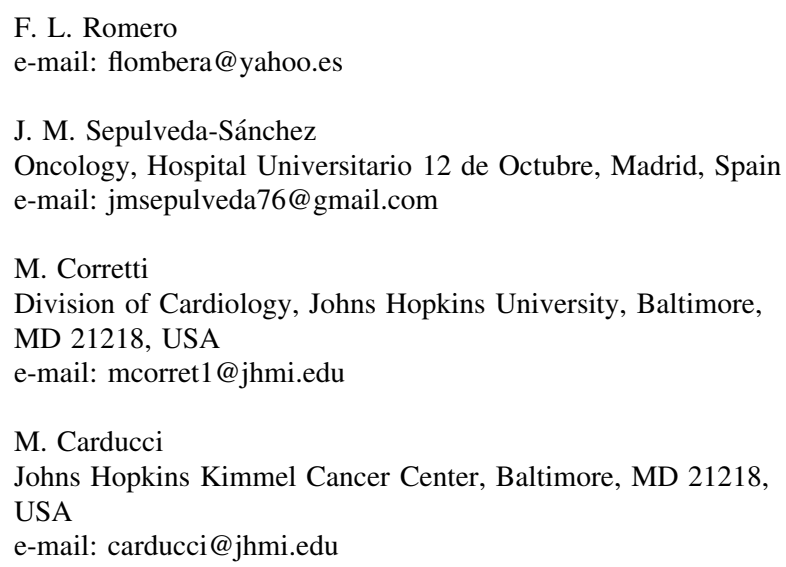




\section{Introduction}

Transforming growth factor-beta (TGF- $\beta$ ) signaling plays an important role in the development of cardiovascular organs and is also a key regulator of cardiovascular remodeling after injury $[1,2]$. Its important role in ontogenesis of the heart was identified by knocking out TGF- $\beta$ signaling proteins [3]. TGF- $\beta$ ligands (TGF- $\beta 1$, TGF- $\beta 2$, and TGF- $\beta 3$ ) regulate diverse biological functions [4]. All three ligands can bind to a specific receptor by first engaging the TGF- $\beta$ receptor type I (TGF- $\beta$ RI or ALK5), which then heterodimerizes with the TGF- $\beta$ RII. This heterodimer complex phosphorylates the intracellular proteins SMAD2 and SMAD3, which initiate an activation cascade to induce several nuclear transduction proteins. By knocking out either the ligands or the SMAD proteins, the development of the heart can be blunted and can lead to intrauterine death [5].

In cardiovascular disease, TGF- $\beta$ signaling has been associated with remodeling of the heart after myocardial infarction and its overexpression has been associated with heart failure [6]. Preclinical models have shown that blocking TGF- $\beta$ signaling with pharmacological agents can prevent injury-induced cardiomyopathies and their associated pathologies [7]. In vessels, TGF- $\beta$ signaling regulates inflammatory responses of the endothelium and smooth muscle to injury [8]. Shear/stress stimuli in the vessels are one of the key inducers of TGF- $\beta$ signaling [9]. This activation of TGF- $\beta$ signaling can prevent aneurysm formation, but is present in aneurysms despite a loss of function in the TGF- $\beta$ signaling pathway [10]. Such a condition is observed in patients with Loeys-Dietz Syndrome (LDS), a subset of Marfan Syndrome, where patients present with aortic dilatation and thoracic aneurysms [11]. In such patients and also in animal models mimicking the condition of LDS patients, TGF- $\beta$ signaling is induced, despite the genetic evidence in loss of function. Toxicology studies

\author{
M. Dolan \\ Department of Cardiology and Cardiovascular Disease, Saint \\ Louis University Hospital, St. Louis, MO 63103, USA \\ e-mail: melda@tetranet.net \\ I. Gueorguieva · A. L. Cleverly \\ Eli Lilly and Company, Erl Wood, UK \\ e-mail: gueorguieva_ivelina@lilly.com \\ A. L. Cleverly \\ e-mail: cleverly_ann_louise@lilly.com \\ N. S. Pillay $\cdot$ M. M. Lahn $(\bowtie)$ \\ Eli Lilly and Company, Building 31/4, 893 S. Delaware St., \\ Indianapolis, IN 46285, USA \\ e-mail: MichaLahn@aol.com \\ N. S. Pillay \\ e-mail: pillay_sada_n@lilly.com
}

with TGF- $\beta$ inhibitors that block TGF- $\beta$ RI/ALK5 have reported toxicities that share the cardiovascular findings in LDS patients [12]. Such findings included structural changes of the heart valve and aneurysms of the ascending aorta and aortic arch. These observations have discouraged the clinical development of small molecule inhibitors. LY2157299 monohydrate (LY2157299) is a TGF- $\beta$ RI kinase inhibitor that interrupts the receptor-mediated signaling cascade. Hence, it was critical to develop a therapeutic window for the safe administration of LY2157299 during a first-in-human dose (FHD) study [13, 14]. During the FHD study, the administration of LY2157299 was accompanied with a comprehensive and prospective cardiac safety monitoring. Cardiac safety evaluations including echocardiography/Doppler, plasma markers of cardiac function, electrophysiological evaluations, and radiographic imaging to assess the ascending aorta and aortic arch for aneurysm formation were used.

The results of this FHD study of LY2157299 are described herein. Overall, the selected dose range of LY2157299 was safe, and no significant cardiac toxicities were observed. This monitoring approach is currently being extended to all other ongoing trials with LY2157299.

\section{Methods}

\section{Patients}

As previously described [13], patients who had a histologic or cytologic diagnosis of cancer for which no proven effective therapy existed were included in the first two cohorts. Starting with cohort 3, only patients with relapsed and progressive glioblastoma were eligible for this study. All patients had to have disease that was measurable or non-measurable as defined by the Response Evaluation Criteria in Solid Tumors (RECIST) and for patients starting on cohort 3 onward as defined by Macdonald criteria [15]. All patients had to have performance status of $\leq 2$ on the Eastern Cooperative Oncology Group (ECOG) scale. Patients were required to have adequate hematologic, hepatic, and renal function, and discontinued all previous therapies for cancer at least 4 weeks prior to the study enrollment. Exclusion criteria included medically uncontrolled cardiovascular illness and medically significant electrocardiogram (ECG) anomalies. Patients who had major abnormalities documented by echocardiography/ Doppler, such as moderate or severe heart valve function defect and/or left ventricular ejection fraction (LVEF) of $\leq 50 \%$, were excluded from the study. Patients with tricuspid (trace or mild), pulmonary, mitral (trace or mild), or aortic (trace or mild) regurgitation by Doppler techniques were allowed to enter the study. 
Study Design

The study was conducted according to the principles of good clinical practice, applicable laws and regulations, and the Declaration of Helsinki. Each institution's review board approved the study and all patients signed an informed consent document before study participation.

LY2157299 was evaluated in a multicenter, open-label, non-randomized, dose escalation First-in-Human Phase 1 study (Fig. 1). There were three parts in the study: Part A was a dose escalation and enrolled patients with advanced or metastatic cancer and then only glioblastoma patients for the remainder of the study. Doses were escalated to a predetermined top dose of $300 \mathrm{mg} /$ day [13]. Each cohort enrolled at least 3 patients and the number of patients per cohort was adjusted based on the pharmacokinetic (PK) profile and variability. In Part B, LY2157299 was combined with lomustine at two doses, 160 and $300 \mathrm{mg} /$ day. Part $\mathrm{C}$ was designed as a relative bioavailability (RBA) study; all patients remained on study treatment after the RBA phase was completed and were then dosed with $300 \mathrm{mg} /$ day LY2157299 monotherapy.

Treatment

LY2157299 was given orally at doses of 20, 40, 80, 120, and $150 \mathrm{mg}$ twice daily as a tablet in the morning and evening. Patients in the first two cohorts received LY2157299 daily as part of a 28-day cycle. Starting with cohort 3, all patients received LY2157299 on Day 1-14 of each 28-day cycle. No dose adjustments or reductions were allowed.

\section{Safety Assessments}

Safety was evaluated in patients who received at least one dose of LY2157299. Safety assessment was based on the summaries of adverse events (AEs) including severity (as defined by Common Terminology Criteria for Adverse Events version 3.0 (CTCAE, v3.0) and possible relationship to study drug, dose-limiting toxicities (DLTs) and laboratory changes at each dose level. Standard laboratory tests included chemistry, hematology, and urinalysis panels. Safety was also analyzed by ECG using a standardized assessment [16], echocardiography/Doppler [17], and additional laboratory tests specifically linked to cardiac toxicity, such as brain natriuretic peptide (BNP), troponin I, high-sensitivity C-reactive protein (hs-CRP), and cystatin C [18] (Figs. 1, 2). Besides the assessment of acute DLT detailed below, serum monitoring for cardiotoxicity was carried out beyond Cycle 1. Assessments were performed at the end of every other cycle starting at Cycle 2, except for cystatin $\mathrm{C}$ and hs-CRP which were taken at the end of every cycle, until study treatment discontinuation.
Fig. 1 Study design of the firstin-human dose study with LY2157299 and timing of the cardiovascular assessments

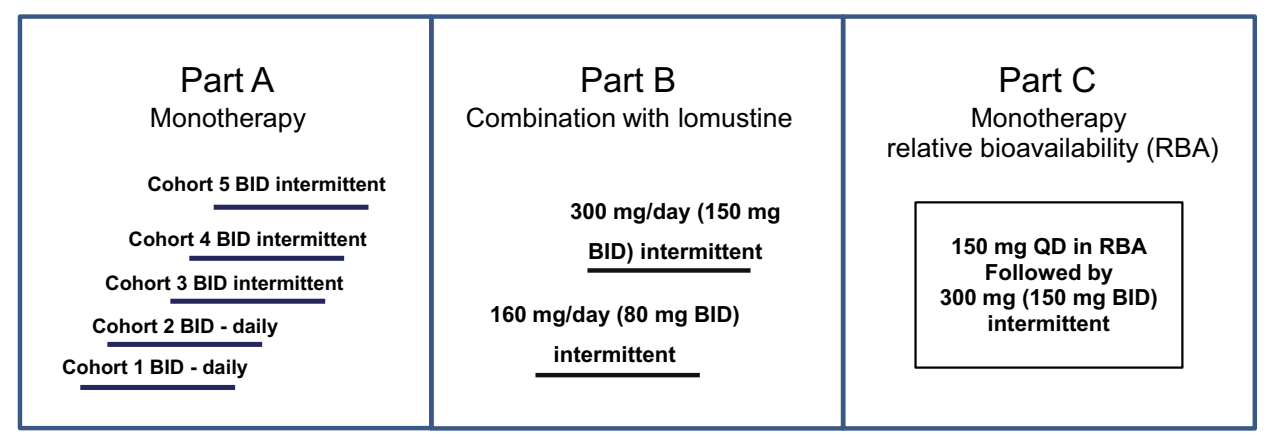

Abbreviations: BID, twice daily; QD, once per day

\begin{tabular}{|c|c|c|c|c|c|c|c|c|}
\hline \multirow[t]{2}{*}{ Examination } & \multicolumn{2}{|c|}{$\begin{array}{c}\text { Pre-study } \\
\text { (days) }\end{array}$} & \multicolumn{3}{|c|}{$\begin{array}{l}\text { Cycle } 1 \\
\text { (days) }\end{array}$} & \multicolumn{3}{|c|}{$\begin{array}{l}\text { Cycle } 2 \text { - onward } \\
\text { (days) }\end{array}$} \\
\hline & 14 & 7 & 1 & $12 \pm 2$ & $26 \pm 2$ & 1 & $12 \pm 2$ & $26 \pm 2$ \\
\hline $\begin{array}{l}\text { Vital signs } \\
\text { (blood pressure and heart rate) }\end{array}$ & $x$ & & $x$ & $x$ & & $x$ & $x$ & \\
\hline $\begin{array}{l}\text { Echocardiography/Doppler } \\
\text { (after cycle 2: every } 2 \text { cycles) }\end{array}$ & $\mathrm{x}$ & & & & $x$ & & & $x$ \\
\hline $\begin{array}{l}\text { CT scan of the aorta } \\
\text { (after cycle 3: every } 2 \text { cycles) }\end{array}$ & $\mathrm{x}$ & & & & $x$ & & & $x$ \\
\hline ECG & $\mathrm{x}$ & & $x$ & $x$ & $x$ & & & $x$ \\
\hline Troponin I + BNP & & $x$ & & & $x$ & & & $x$ \\
\hline hs-CRP & & $x$ & & & $x$ & & & $x$ \\
\hline Cystatin C & & $x$ & & $x$ & $x$ & & $x$ & $x$ \\
\hline
\end{tabular}


Fig. 2 Overview of the parameters of the cardiovascular monitoring implemented during the first-in-human dose study with LY2157299

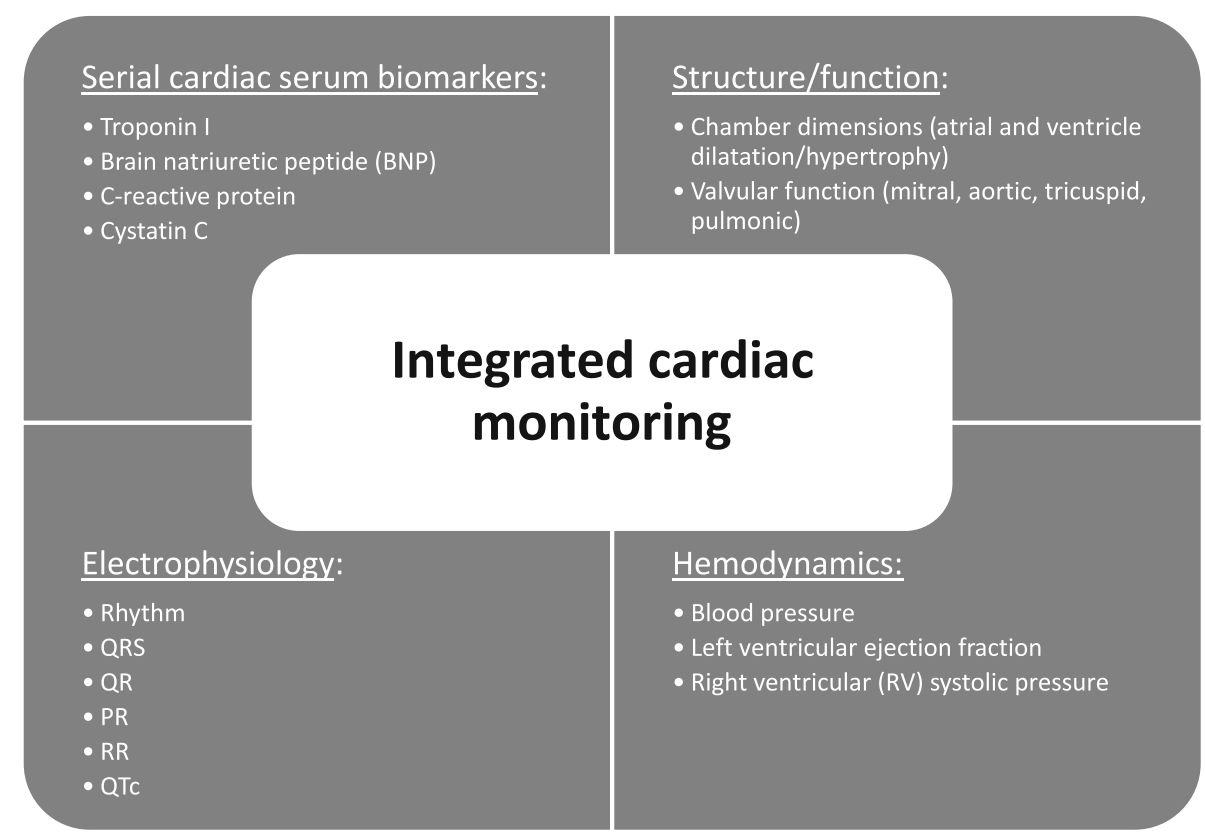

Computer tomography (CT) scans or magnetic resonance images (MRI) of the thoracic aorta specifically assessing potential aneurysms of the ascending aorta and aortic arch were performed based on institutional imaging procedures [19]. Any clinically significant abnormal results were recorded as AEs. If there were clinically significant cardiac findings at discontinuation, echocardiography/Doppler and ECGs were to be repeated every 2 months for 6 months. In the event of no cardiac findings at study treatment discontinuation, one more echocardiography and ECG were planned after 2 months, unless the patient had started another treatment.

\section{D Echocardiography/Color Spectral Doppler}

Echocardiography/Doppler were performed according to a standard protocol and interpreted as per recommendations of echocardiography societies [17]. All images were submitted to a central echocardiologist who reviewed all images based on pre-specified variables (Table 1). During the study, an echocardiography alert process was implemented in order to ensure close monitoring of every patient, and reconciliation was pre-specified between local and central echocardiography review to ensure consistent grading of abnormality (Fig. 3).

\section{DLT Assessment}

Dose escalation to the second cohort proceeded after three patients completed one treatment cycle without a DLT and after careful assessment of their PK and safety information.
Dose escalation to each subsequent dose was based on a combination of the number of DLTs at the dose tested, aggregate safety profile, and predicted exposure of area under the curve. Hematologic or non-hematologic toxicity with grade $\geq 3$ was considered as a DLT in patients treated with study medication at different dose levels according to the National Cancer Institute and the CTCAE, v3.0. Specific DLT criteria for cardiac parameters were defined to be an increase of one or more grades of the semi-quantitative valvular insufficiency, left ventricular function, or right ventricular systolic pressure (normal, mild, moderate, or severe based on local laboratory limits). If a patient was normal at baseline and after the first cycle increased to mild, then a repeat echocardiography should be performed after 14 days. If results confirmed mild grade at repeat echocardiography, then patient was to be discontinued. If findings were normal, then the patient continued treatment per study protocol. In addition, an increase in left atrial or ventricular chamber size of 2 and $1 \mathrm{~cm}$, respectively, or any evidence of damage to the heart's large vessels from the CT scan would also be considered a DLT. For the serum cardiac safety markers, concentrations of $\mathrm{BNP} \geq 3$ times the baseline value and above the upper limit of normal (ULN) and sustained at two consecutive scheduled blood draws, and/or concentrations of troponin I above the ULN were also considered DLTs.

\section{Statistical Analysis}

The primary objective of this FHD study was to determine a safe and tolerable dose for future Phase 2 studies. This 
Table 1 List of cardiac markers assessed

\begin{tabular}{|c|c|}
\hline & Normal ranges \\
\hline \multicolumn{2}{|l|}{ Serum biomarkers } \\
\hline Troponin I & $0-0.3 \mu \mathrm{g} / \mathrm{L}$ \\
\hline $\mathrm{BNP}$ & $\begin{array}{l}0 \leq \text { age }<45: 2.7-33 \mathrm{ng} / \mathrm{L} \\
45 \leq \text { age } \leq 54: 2.7-46.7 \mathrm{ng} / \mathrm{L} \\
55 \leq \text { age }<65: 2.7-53.2 \mathrm{ng} / \mathrm{L} \\
65 \leq \text { age }<75: 2.7-72.3 \mathrm{ng} / \mathrm{L} \\
75 \leq \text { age }<111: 2.7-176 \mathrm{ng} / \mathrm{L}\end{array}$ \\
\hline hs-CRP & $0-3 \mathrm{mg} / \mathrm{L}$ \\
\hline Cystatin C & $0.53-0.95 \mathrm{mg} / \mathrm{L}$ \\
\hline \multicolumn{2}{|l|}{ Echocardiography/Doppler } \\
\hline \multicolumn{2}{|l|}{ Continuous variables (normal range) } \\
\hline LV internal dimension (diastolic) & $\leq 2.8 \mathrm{~cm} / \mathrm{m}^{2}$ \\
\hline LA volume (end-systolic) & $\leq 36 \mathrm{~mL} / \mathrm{m}^{2}$ \\
\hline LA dimension (end-systolic) & $1.9-4.0 \mathrm{~cm}$ \\
\hline LV ejection fraction & $\geq 50 \%$ \\
\hline LV mass & $\begin{array}{l}\leq 115 \mathrm{~g} / \mathrm{m}^{2}-\text { male } \\
\leq 99 \mathrm{~g} / \mathrm{m}^{2}-\text { female }\end{array}$ \\
\hline PA systolic pressure & $\leq 40 \mathrm{mmHg}$ \\
\hline Pulmonary flow velocity acceleration time & $\geq 120 \mathrm{~ms}$ \\
\hline Mitral deceleration time & $\geq 160 \mathrm{~ms}$ and $\leq 220 \mathrm{~ms}$ \\
\hline Mitral E/A ratio & $\geq 0.75$ and $\leq 1.5$ \\
\hline $\mathrm{E} / \mathrm{Em}$ & $<10$ \\
\hline Systolic blood pressure & Measurements in $\mathrm{mmHg}$ \\
\hline Diastolic blood pressure & Measurements in $\mathrm{mmHg}$ \\
\hline \multicolumn{2}{|l|}{ Semi-quantitative variables (severity scale) } \\
\hline RA dilation & Normal, mild, moderate, severe \\
\hline RV dilation & Normal, mild, moderate, severe \\
\hline Mitral regurgitation & Absent, trace, mild, moderate, severe \\
\hline Aortic regurgitation & Absent, trace, mild, moderate, severe \\
\hline Pulmonic regurgitation & Absent, present \\
\hline Tricuspid regurgitation & Absent, present \\
\hline Wall motion & Normal/abnormal \\
\hline Pericardial effusion & Absent, small, moderate, large \\
\hline \multicolumn{2}{|l|}{ Electrocardiogram } \\
\hline \multicolumn{2}{|l|}{ Standard measurements } \\
\hline \multicolumn{2}{|l|}{ Hemodynamic measurements } \\
\hline Blood pressure & 90/60-140/90 mmHg \\
\hline Heart rate & $50-100$ beats/min \\
\hline
\end{tabular}

Per-protocol attachment $\mathrm{E} / \mathrm{Em}<15$ not $<10$ as in worksheet. Mitral and aortic valve area for evidence of stenosis should not be less than 2 and $1.5 \mathrm{~cm} / \mathrm{m}^{2}$, respectively, but data were not collected $B N P$ brain natriuretic peptide, $h s-C R P$ high-sensitivity C-reactive protein, $L A$ left aortic, $L V$ left ventricle, $P A$ pulmonary artery, $R A$ right aortic, $R V$ right ventricle tables to summarize maximum changes in severity after dosing were created for overall ECG evaluation. The frequency of patients experiencing increases from baseline in QTcF were listed by category: 0-30, >30-60, and >60 ms. For valvular regurgitation parameters, all measurements for patients who experienced an increase in severity of at least one grade are listed, together with the time-matched systolic blood pressure. This detail was provided in order to help interpret the event. Line plots over time for serum measurements and ECG parameters (together with normal 


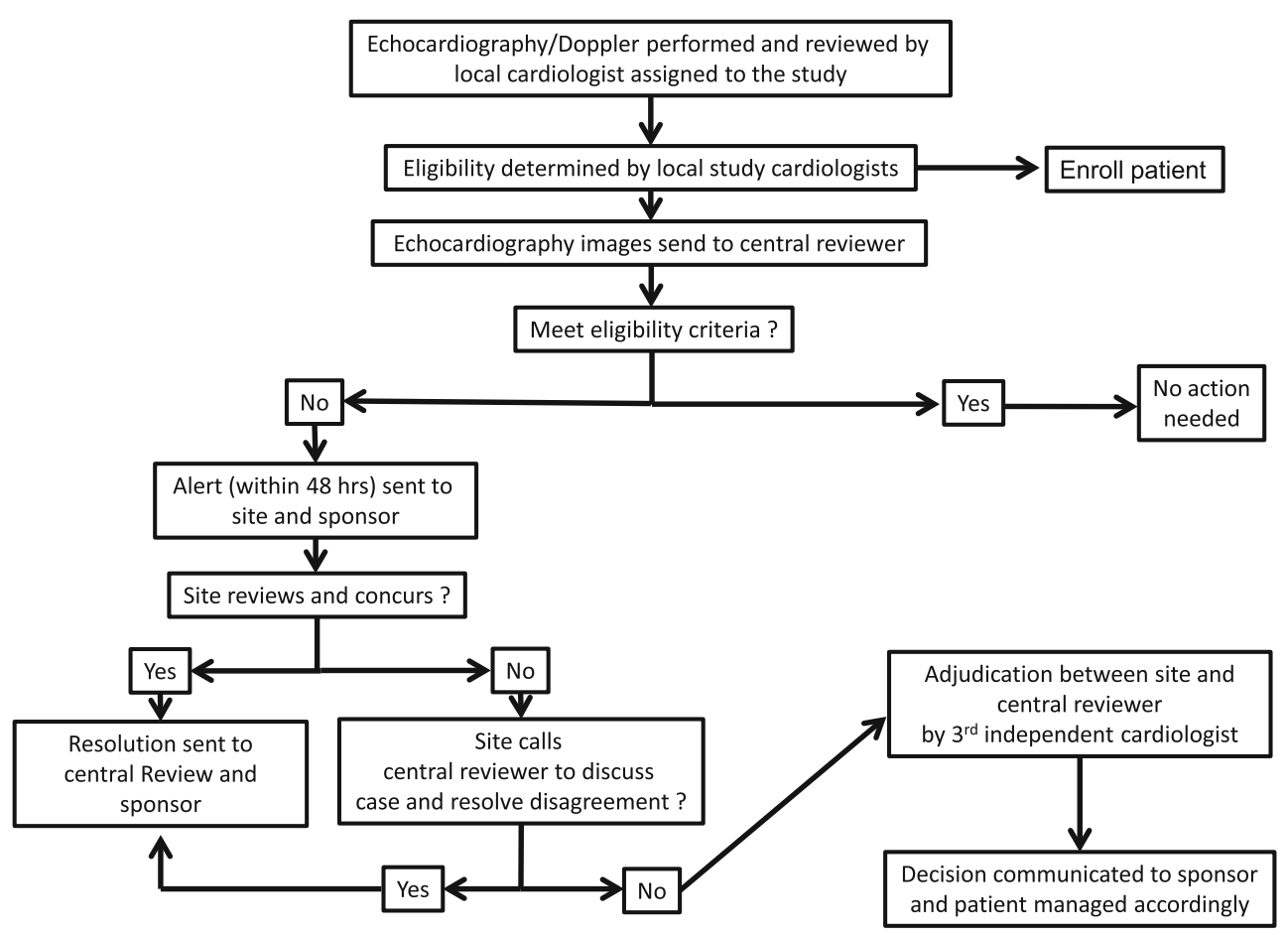

Fig. 3 Alert and adjudication process of echocardiography/Doppler assessments between local and central echocardiography readers

limits where appropriate) and box-whisker plots for blood pressure and left ventricular fraction are provided.

\section{Results}

A total of 79 patients were enrolled into this FHD study from 2006 to 2012, which included a period of 2 years when the study was placed on clinical hold awaiting new animal toxicology data. The majority of the patients were male in Parts A and B of the study; in Part C, there were more females (Table 2). Most patients were younger than 60 years. In Part A, there was a higher proportion of patients who had either a lower grade glioma or secondary glioma compared to patients enrolled in Parts B and C. Overall, most patients had a good performance status (ECOG 0 or 1 ) at the time of their cancer progression and after failing to respond to previous effective anticancer therapies (Table 2). Because of the entry criteria, all patients had an unremarkable cardiac function prior to the study entry.

\section{Concomitant Cardiac Medications}

The low number of cardiac medications suggested that patients had relatively good cardiovascular statuses (Table 2). The most common cardiac medication was enalapril $(6 / 79,7.6 \%)$ followed by angiotensin II receptor blockers $(5 / 79,6.3 \%)$.
Safety Measures: Treatment-Emergent Adverse Events

Of 79 patients dosed, 37 died during the study -36 due to tumor progression and one related to pneumonia. One patient (in Part A in the $300 \mathrm{mg} /$ day cohort) was identified as having a DLT of grade 4 thrombocytopenia. The patient completed Cycle 2 but died due to disease progression before he fully recovered from this event. In the entire study, 53 patients $(53 / 79 ; 67 \%)$ experienced at least one grade 3 or 4 adverse event, of which the events of 13 (13/ $79 ; 16.4 \%)$ patients were possibly related to study treatment (Table 3$)$. Two patients $(2 / 79 ; 2.5 \%)$ discontinued from study treatment due to platelet reduction (CTCAE v3.0 grades 2 and 4), both considered as possibly related to study treatment.

\section{Plasma/Serum Markers to Assess Cardiac Function}

We used the markers troponin I, BNP and hs-CRP to serially evaluate for myocardial necrosis (troponin I), cardiac failure (BNP), or an inflammatory response (hsCRP) (Fig. 4). One patient on monotherapy had higher than normal troponin I values on Days 122 and 127 postdose. On both occasions, the recorded value was $0.06 \mathrm{ng} / \mathrm{L}$ (ULN $=0.05 \mathrm{ng} / \mathrm{L}$ ). The patient discontinued because of progressive disease on Day 149 and values returned to normal on Day 156. No values were greater than the ULN in patients treated in combination with lomustine (data not 
Table 2 Patient characteristics and concomitant cardiovascular medication

\begin{tabular}{|c|c|c|c|}
\hline Characteristics & $\begin{array}{l}\text { Part A } \\
N=39\end{array}$ & $\begin{array}{l}\text { Part B } \\
N=26\end{array}$ & $\begin{array}{l}\text { Part C } \\
N=14\end{array}$ \\
\hline \multicolumn{4}{|l|}{ Age (years) } \\
\hline Mean (SD) & $51.8(14.88)$ & $44.5(10.35)$ & $59.8(12.74)$ \\
\hline Median (range) & $54.0(22,77)$ & $43.5(25,61)$ & $56.5(34,76)$ \\
\hline \multicolumn{4}{|l|}{$\operatorname{Sex}[n(\%)]$} \\
\hline Male & $30(76.9)$ & $19(73.1)$ & $5(35.7)$ \\
\hline Female & $9(23.1)$ & 7 (26.9) & $9(64.3)$ \\
\hline \multicolumn{4}{|l|}{ Origin $[n(\%)]$} \\
\hline Caucasian & $39(100)$ & $24(92.3)$ & $14(100)$ \\
\hline Hispanic & - & $1(3.8)$ & - \\
\hline West Asian & - & $1(3.8)$ & - \\
\hline \multicolumn{4}{|l|}{$\operatorname{ECOG}[n(\%)]$} \\
\hline 0 & $15(38.5)$ & $3(11.5)$ & $4(28.6)$ \\
\hline 1 & $19(48.7)$ & $17(65.4)$ & $8(57.1)$ \\
\hline 2 & $5(12.8)$ & $6(23.1)$ & $2(14.3)$ \\
\hline Glioma $[n(\%)]$ & $n=30^{\mathrm{a}}$ & $n=26$ & $n=9$ \\
\hline Low grade, Grade II-III & $9(30.0)$ & $4(15.4)$ & $2(22.2)$ \\
\hline Secondary, Grade IV & $5(16.7)$ & $2(7.7)$ & - \\
\hline Primary, Grade IV & $16(53.3)$ & $20(76.9)$ & $7(77.8)$ \\
\hline
\end{tabular}

Drug class generic name

Patients

(n)

$\begin{array}{lr}\text { Cardiovascular drugs } & \\ \text { Alpha and beta blocking agents } & 1 \\ \text { Labetalol } & 1 \\ \text { Atenolol } & 2 \\ \text { Bisoprolol } & 1 \\ \text { Metoprolol tartrate } & \\ \text { Angiotensin-converting enzyme } & 6 \\ \text { inhibitors } & 1 \\ \text { Enalapril } & \\ \text { Lisinopril } & 2 \\ \text { Angiotensin II receptor blockers } & 2 \\ \text { Losartan } & 1 \\ \text { Valsartan } & \\ \text { Olmesartan } & 1 \\ \text { Antiarrhythmics } & 1 \\ \text { Lidocaine } & \\ \text { Flecainide acetate } & \end{array}$

ECOG Eastern Cooperative Oncology Group, $S D$ standard deviation

a Data for two patients are not available

shown). For BNP, no patients on monotherapy met the prespecified toxicity criteria. One patient on combination therapy had concentrations that did not meet the prespecified toxicity criteria and the BNP levels increased 16 -fold from $3.8 \mathrm{ng} / \mathrm{L}$ at baseline to $59.0 \mathrm{ng} / \mathrm{L}$ by Day 56 (ULN age-adjusted was $53.2 \mathrm{ng} / \mathrm{L}$ ). This patient discontinued from study treatment on Day 64 due to tumor progression (Fig. 4). There were some isolated instances of increased hs-CRP, but none were sustained over time. The isolated increases may reflect infection-related reactions, and the lack of sustained (i.e., over several cycles) increases of hs-CRP suggested no clinical concern of toxicity. A reduction of cystatin $\mathrm{C}$ levels is thought to predict the formation of aneurysms and was therefore 
Table 3 Summary of number of patients with TEAEs and CTCAE severity grade by study part and study treatment relatedness

\begin{tabular}{|c|c|c|c|c|}
\hline \multirow[t]{2}{*}{ Study part } & \multicolumn{2}{|l|}{ TEAEs } & \multicolumn{2}{|c|}{ Related to study treatments } \\
\hline & $\begin{array}{l}\geq 1 \text { TEAE } \\
n(\%)\end{array}$ & $\begin{array}{l}\geq 1 \text { Grade } 3 / 4 \\
n(\%)\end{array}$ & $\begin{array}{l}\geq 1 \text { TEAE } \\
n(\%)\end{array}$ & $\begin{array}{l}\geq 1 \text { Grade } 3 / 4 \\
n(\%)\end{array}$ \\
\hline Part A $(N=39)$ & $37(95)$ & $24(62)$ & $10(26)$ & $3(8)$ \\
\hline Part B $(N=26)$ & $26(100)$ & $22(85)$ & $15(58)$ & $8(31)$ \\
\hline Part C $(N=14)$ & $14(100)$ & $7(50)$ & $3(21)$ & $2(14)$ \\
\hline Total $(N=79)$ & 77 (97) & $53(67)$ & $28(35)$ & $13(16)$ \\
\hline
\end{tabular}

Study treatment relatedness in Part B is to either LY2157299, lomustine or both

CTCAE common terminology criteria for adverse events, TEAEs treatment-emergent adverse events

measured beginning with Part A cohort 3 onward (18). The use of this plasma assay in conjunction with the radiographic assessment of the large vessels using contrast CT scans represented an additional risk evaluation in patients treated with LY2157299. A sustained reduction in cystatin $C$ levels that may have indicated the development of aneurysms was not apparent for any patient, whether dosed with monotherapy or in combination with lomustine (Fig. 4).

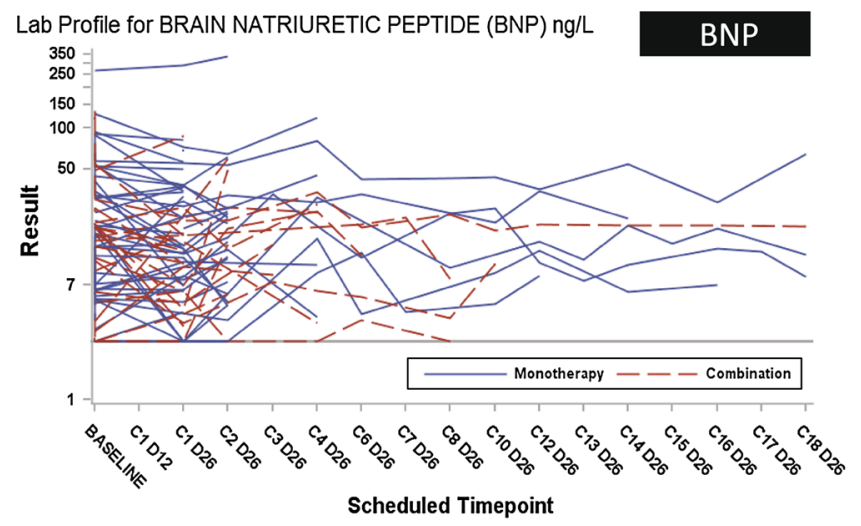

Note: The horizontal line on the plot represents the lower normal limit.
Electrocardiogram

As part of the comprehensive cardiac safety evaluation of LY2157299, electrophysiological changes were monitored by local and central assessments by cardiologists. Based on the preclinical studies (in vitro and animal in vivo studies), LY2157299 was not associated with QTc prolongation, but this additional monitoring was performed to complement the other cardiac monitoring examinations. We obtained

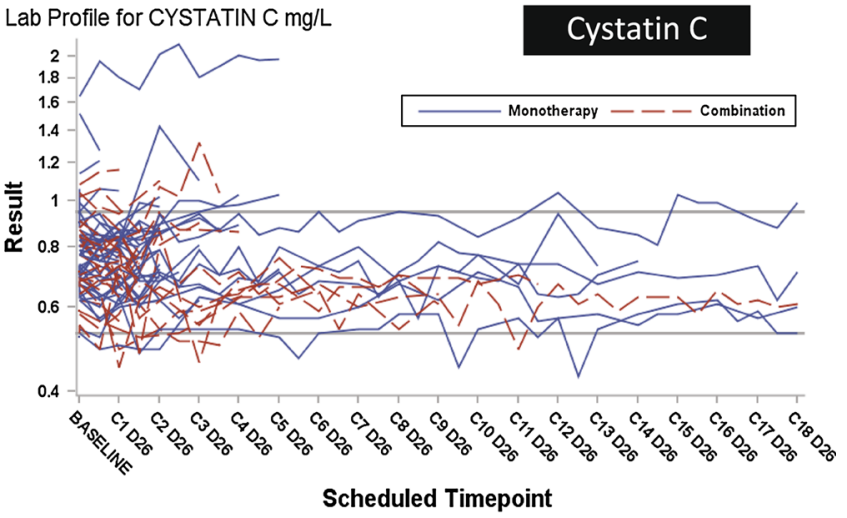

Note: The horizontal lines on the plot represents the upper and lower normal limit.

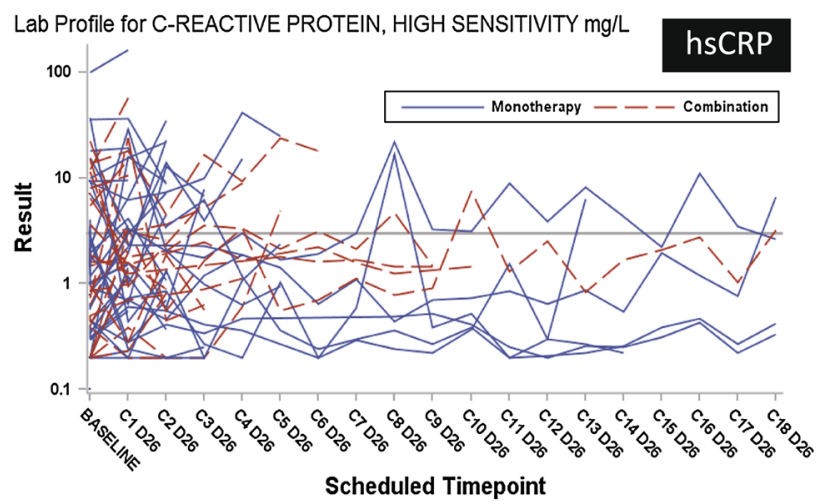

Note: The horizontal line on the plot represents the upper normal limit.

Fig. 4 Serum cardiac markers and changes over time for brain natriuretic factor (BNP), cystatin $\mathrm{C}$ and high-sensitive $\mathrm{C}$-reactive protein (hs-CRP). Horizontal lines reflect the norm values. Blue lines represent patients who received LY2157299 as monotherapy and red for patients who were treated with the combination of LY2157299 and lomustine 
Table 4 Summary of changes from baseline in overall electrocardiogram assessments and in QTc (Fridericia)

\begin{tabular}{|c|c|c|}
\hline Monotherapy & & \\
\hline \multicolumn{3}{|l|}{ Baseline } \\
\hline Missing or normal ECG & \multicolumn{2}{|l|}{ Abnormal ECG } \\
\hline $22 / 42(52 \%)$ & \multicolumn{2}{|l|}{$20 / 42(48 \%)$} \\
\hline \multicolumn{3}{|l|}{ Change from baseline } \\
\hline Normal ECG to abnormal & \multirow{2}{*}{\multicolumn{2}{|c|}{$\begin{array}{l}\text { Abnormal to normal } \\
1 / 42(2 \%)\end{array}$}} \\
\hline $11 / 52(26 \%)$ & & \\
\hline \multicolumn{3}{|l|}{ Combination } \\
\hline \multicolumn{3}{|l|}{ Baseline } \\
\hline Normal ECG & \multicolumn{2}{|l|}{ Abnormal ECG } \\
\hline $8 / 18(44 \%)$ & \multicolumn{2}{|l|}{$10 / 18(56 \%)$} \\
\hline \multicolumn{3}{|l|}{ Change from baseline } \\
\hline Normal ECG to abnormal & \multirow{2}{*}{\multicolumn{2}{|c|}{$\begin{array}{l}\text { Abnormal to normal } \\
0 / 18(0 \%)\end{array}$}} \\
\hline $6 / 18(33 \%)$ & & \\
\hline Increase $\mathrm{QTcF}$ interval & $\begin{array}{l}\text { Monotherapy } \\
n / N(\%)\end{array}$ & $\begin{array}{l}\text { Combination } \\
n / N(\%)\end{array}$ \\
\hline 0 and $30 \mathrm{~ms}$ & $30 / 44(68)$ & $16 / 19(84)$ \\
\hline 30 and $60 \mathrm{~ms}$ & $10 / 44(23)$ & $3 / 19(16)$ \\
\hline$>60 \mathrm{~ms}$ & $0 / 44(0)$ & $0 / 19(0)$ \\
\hline
\end{tabular}

Only includes patients who have both baseline and post-dose electrocardiogram measurements

$E C G$ electrocardiogram

complete ECG readings in 60 patients $(60 / 79 ; 76 \%)$ and normal ECG readings were observed in $50 \%(30 / 60)$ at baseline. There was a change to abnormal at least once during treatment in approximately one-third of all patients (Table 4). For patients who continued on treatment, there was no general increase in QTcF or PR rate (Fig. 5). A change of $>30 \mathrm{~ms}$ in QTcF (Fridericia) was observed in $10 / 44$ patients $(22.7 \%)$ during monotherapy treatment (Table 4). There was no patient who had a QTcF prolongation of more than $60 \mathrm{~ms}$ or had an excursion over 500 ms. LY2157299 plasma concentration and ECG measurements were not time-matched; however, $16 \%$ of observations were within $10 \mathrm{~min}, 33 \%$ were within 30 min, $54 \%$ within $1 \mathrm{~h}$ and $99 \%$ within $2 \mathrm{~h}$ of each other. We used information from a predictive population PK model [14], simulating the individual patient plasma concentration at the exact time of ECG measurement to investigate whether there was a potential for LY2157299 to be associated with QTcF prolongation. Based on this model, we were reassured that the concentrations in humans were not likely to be associated with any QTcF prolongation (data not shown).
Computer Tomography Scan of the Upper Thorax

Using CT imaging, we did not find any evidence of changes to the ascending aorta or aortic arch.

\section{Blood Pressure}

Blood pressure was evaluated after the first administration during Cycle 1 in Parts A and B of the study. This assessment was designed to determine whether there was an immediate, short-term effect of LY2157299 on blood pressure. Short-term evaluation for Part $\mathrm{C}$ was not carried out. During this short-term evaluation (during the first hours post-LY2157299 administration), no changes in systolic and diastolic blood pressure were observed (Fig. 6). LY2157299 had no influence on blood pressure as described for anti-angiogenic compounds.

\section{Echocardiography/Doppler}

The transthoracic 2D echocardiography/color Spectral Doppler examination assessed overall cardiac structure and 

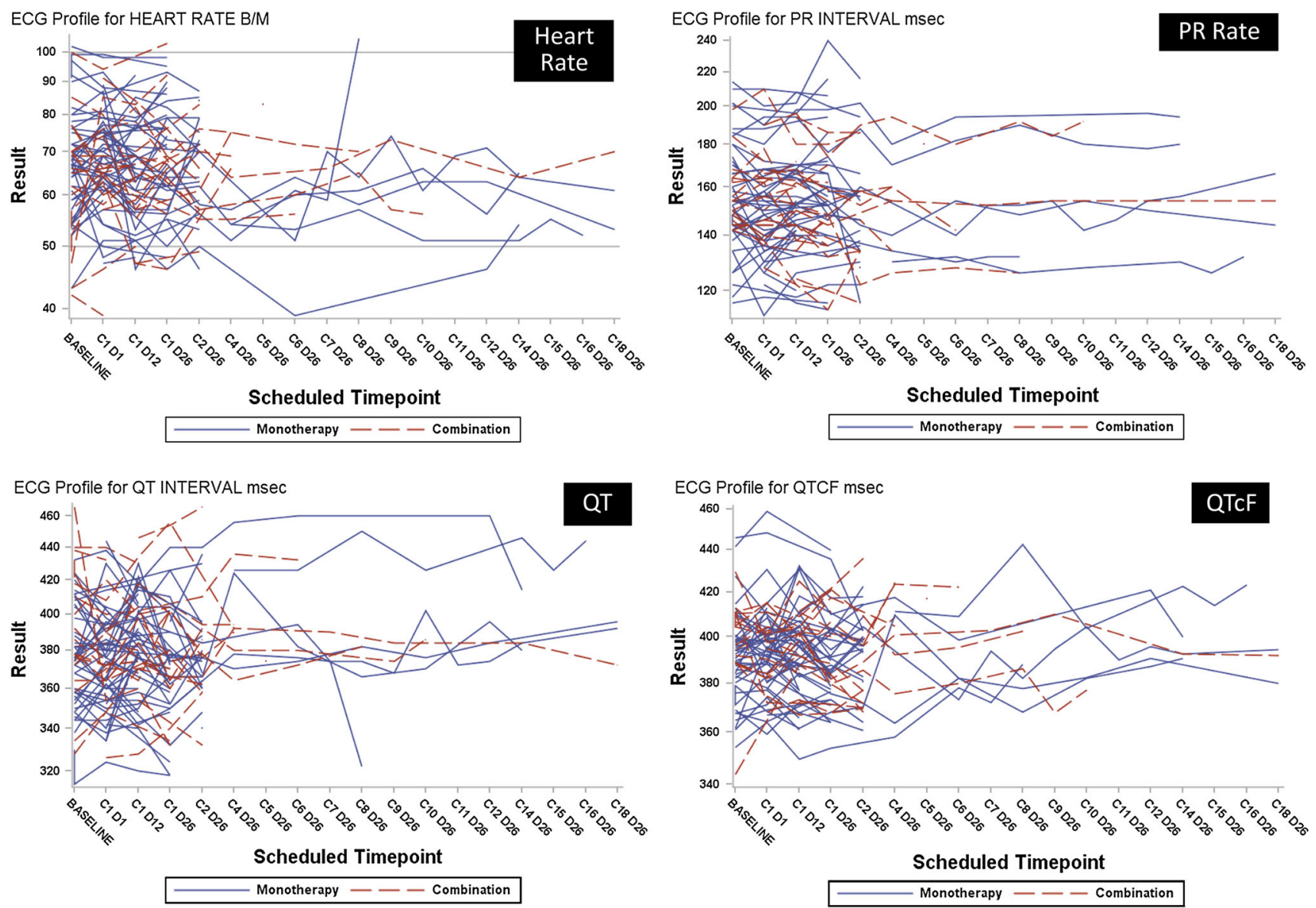

Fig. 5 Select electrocardiogram (ECG) parameters. Heart rate as assessed at time of ECG readings. PR rate, QT, and QTcF. Blue lines represent patients who received LY2157299 as monotherapy and red for patients who were treated with the combination of LY2157299 and lomustine

function, and potential toxicity risks related to damage to the heart valves, myocardium, or pericardium. The left ventricular function was not changed, including in patients who received treatments longer than six cycles (Fig. 7). In 15 patients, there was a change from baseline that was considered per protocol and central review as potentially pathological, because the valve function suggested a change from a lower risk to a moderate risk. Another patient experienced a change by two severity grades (absent to mild) (Table 5). All these changes were not considered medically significant, and the patient who experienced a change of two severity levels had no other signs of cardiac injury, including plasma BNP or troponin I levels. In this patient, a pulmonary embolism was detected, which may contribute to the changes observed in the echocardiography/Doppler imaging.

\section{Discussion}

We report on a prospective and comprehensive cardiac monitoring strategy to assess potential cardiac toxicities for the TGF- $\beta$ inhibitor LY2157299. Because of the toxicities observed in animals with TGF- $\beta$ RI inhibitors, we established a cardiac monitoring approach that would detect early signs of cardiac dysfunction. The cardiac toxicity in animals was focused on two major toxicities: (a) valvular changes with localized inflammatory infiltrates and (b) aneurysms observed in dogs and rats treated with LY2157299 continuously for 6 months. In oncology, cardiac toxicity assessments have become increasingly important as preventative strategies are needed to reduce chemotherapy-related cardiac toxicities [20]. Despite this need to assess cardiac safety comprehensively, clinical trials in cancer patients seem to continue to underestimate the risk of cardiac toxicity [21]. This discrepancy may have two main reasons: (1) Toxicities in animal toxicology studies are viewed as not consistently predictive for humans; (2) cardiac toxicities are seen only after several years post-treatment as observed in survivors of pediatric cancer [22]. With treatments containing anthracyclines and bevacizumab, cardiac toxicities are observed in a continuum of time, some occur during the treatment and other 

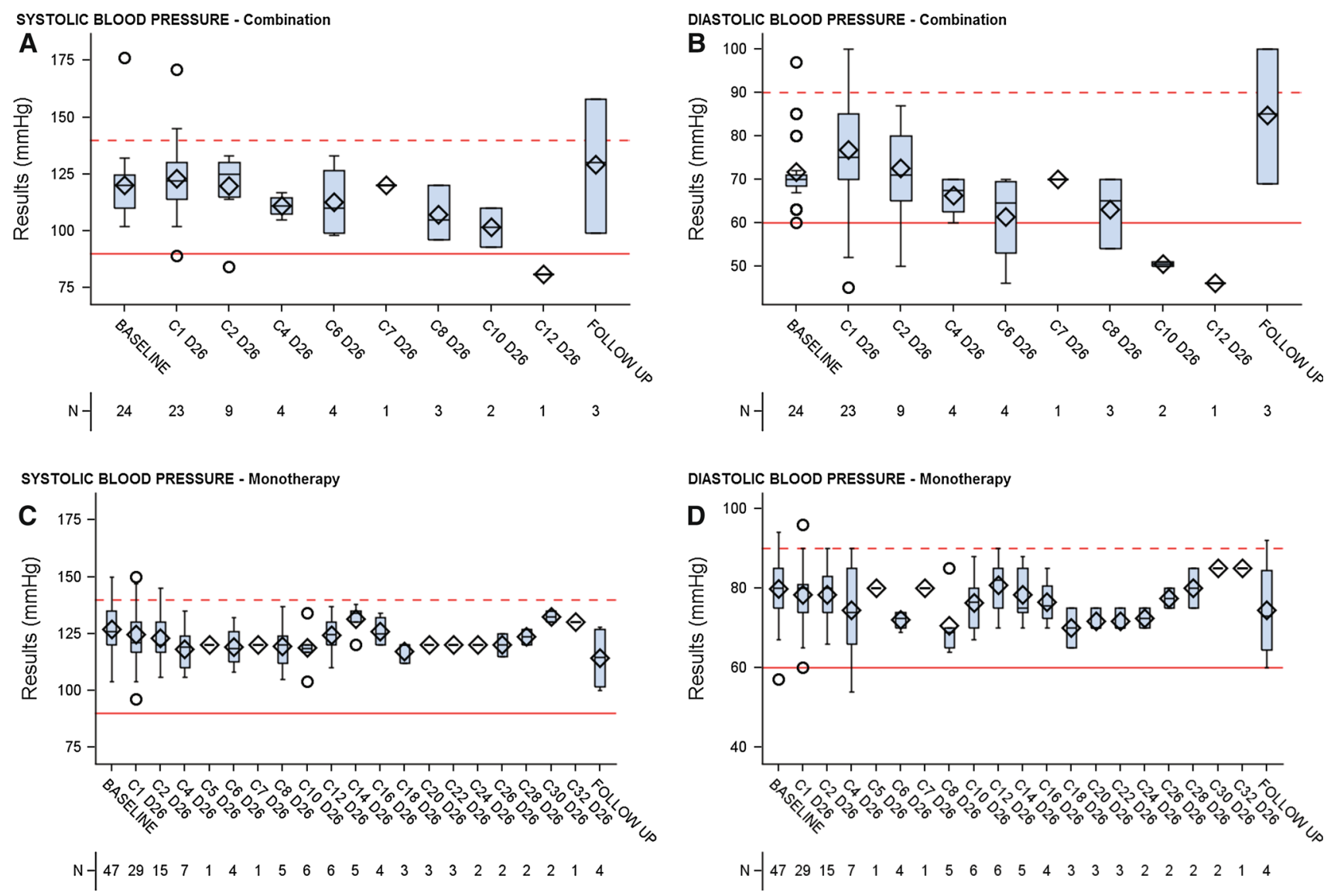

Fig. 6 Blood pressure changes over time after the first dose of LY2157299 using cuff-measurements (horizontal lines represent normal ranges). Systolic and diastolic blood pressure values over time during the long-term treatment for patients receiving

LY2157299 monotherapy [systolic blood pressure (c); diastolic blood pressure (d)] and combination of LY2157299 and lomustine [systolic blood pressure (a); diastolic blood pressure (b)]
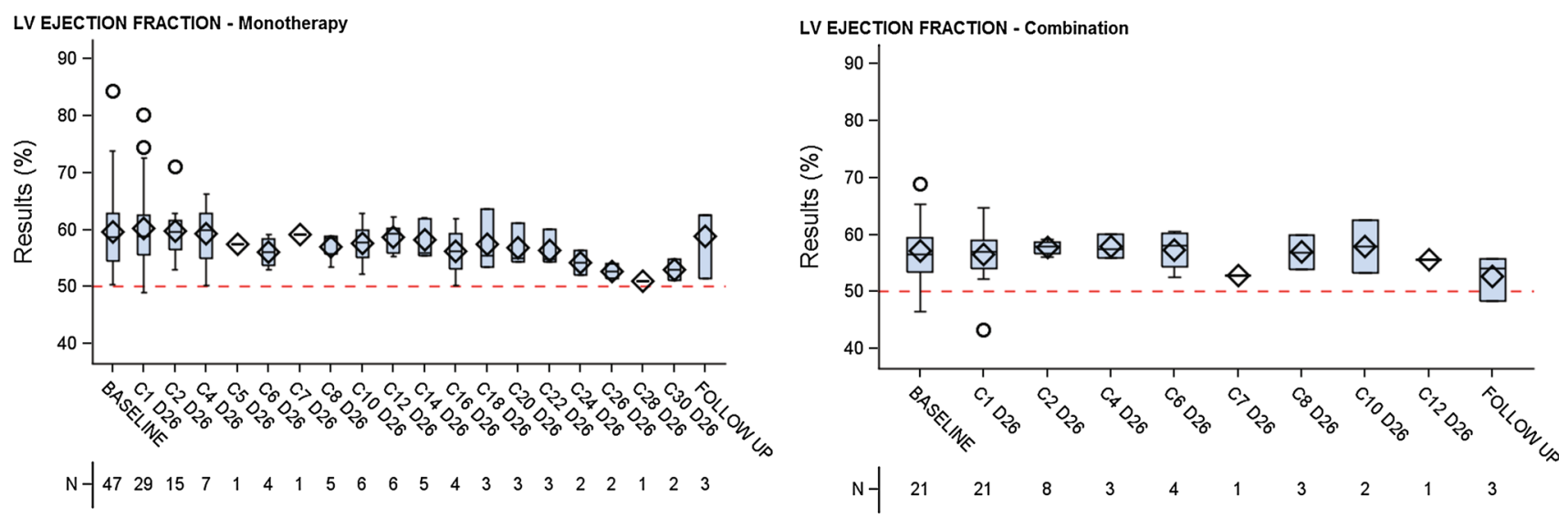

Fig. 7 Left ventricular (LV) ejection fraction for monotherapy LY2157299 and combination of LY2157299 and lomustine (red line represents the normal value and open circles are patients outside of the confidence intervals)

patients exhibit the toxicity after treatment [23, 24]. In contrast to such variable or delayed toxicities, LY2157299 or similar TGF- $\beta$ RI small molecular inhibitors are associated with an immediate cardiac toxicity in animals.
Hence, the implementation of comprehensive cardiac toxicity monitoring during the FHD study was imperative. While we expected that the anticipated therapeutic window would not be associated with cardiac toxicity, we needed to 
Table 5 Listing of patients whose aortic, mitral, and tricuspid valve assessment by deterioration of at least 1 category of severity

\begin{tabular}{|c|c|c|c|c|c|c|}
\hline \multirow[t]{2}{*}{ Patient } & \multirow[t]{2}{*}{ Visit } & \multicolumn{4}{|c|}{ Valvular assessment $($ aortic $=\mathrm{A}$, mitral $=\mathrm{M}$, tricuspid $=\mathrm{T})$} & \multirow{2}{*}{$\begin{array}{l}\text { Systolic blood } \\
\text { pressure }(\mathrm{mmHg}\end{array}$} \\
\hline & & Absent & Trace & Mild & & \\
\hline \multirow[t]{2}{*}{$\mathrm{R} 4$} & Baseline & $\mathrm{A}, \mathrm{M}$ & $\mathrm{T}$ & & & 140 \\
\hline & 1 & & $\mathbf{M}$ & & & 141 \\
\hline \multirow[t]{3}{*}{$\mathrm{R} 30$} & Baseline & $\mathrm{A}, \mathrm{M}$ & $\mathrm{T}$ & & & 104 \\
\hline & $1-14$ & & $\mathbf{M}$ & $\mathbf{T}$ & & $104-138$ \\
\hline & 14 & & $\mathbf{M}$ & $\mathbf{T}$ & & 138 \\
\hline \multirow[t]{3}{*}{ R5 } & Baseline & $\mathrm{A}, \mathrm{M}$ & & $\mathrm{T}$ & & 135 \\
\hline & $1-2$ & & $\mathbf{M}$ & & & $110-120$ \\
\hline & 2 & & $\mathbf{M}$ & & & 110 \\
\hline \multirow[t]{3}{*}{ R6 } & Baseline & $\mathrm{A}, \mathrm{M}, \mathrm{T}$ & & & & 130 \\
\hline & $1-2$ & & $\mathbf{T}$ & & & $140-150$ \\
\hline & 2 & & $\mathbf{T}$ & & & 140 \\
\hline \multirow[t]{3}{*}{$\mathrm{R} 7$} & Baseline & $\mathrm{A}, \mathrm{M}$ & $\mathrm{T}$ & & & 120 \\
\hline & $1-2$ & & $\mathbf{M}$ & & & $110-140$ \\
\hline & 2 & & $\mathbf{M}$ & & & 110 \\
\hline \multirow[t]{3}{*}{$\mathrm{R} 12$} & Baseline & $\mathrm{A}, \mathrm{T}$ & M & & & 140 \\
\hline & $1-2$ & & & $\mathbf{M}$ & $T$ & $125-130$ \\
\hline & 2 & & & $\mathbf{M}$ & $T$ & 130 \\
\hline \multirow[t]{3}{*}{$\mathrm{R} 20$} & Baseline & $\mathrm{A}, \mathrm{M}$ & $\mathrm{T}$ & & & 136 \\
\hline & $1-2$ & & $\mathbf{M}$ & & & $129-134$ \\
\hline & 2 & $M$ & & & & 129 \\
\hline \multirow[t]{3}{*}{$\mathrm{R} 21$} & Baseline & $\mathrm{A}, \mathrm{M}$ & $\mathrm{T}$ & & & 126 \\
\hline & $1-31$ & & M & & & $105-135$ \\
\hline & 31 & $M$ & & & & 135 \\
\hline \multirow[t]{3}{*}{$\mathrm{R} 26$} & Baseline & $\mathrm{A}, \mathrm{M}, \mathrm{T}$ & & & & 134 \\
\hline & $1-2$ & & M & & & $124-130$ \\
\hline & 2 & & M & & & 130 \\
\hline \multirow[t]{3}{*}{$\mathrm{R} 41$} & Baseline & $\mathrm{A}, \mathrm{M}, \mathrm{T}$ & & & & 120 \\
\hline & $1-2$ & & $\mathbf{M}, \mathbf{T}$ & & & 130 \\
\hline & 2 & $M$ & $\mathbf{T}$ & & & 130 \\
\hline \multirow[t]{3}{*}{$\mathrm{R} 42$} & Baseline & A & $\mathrm{M}, \mathrm{T}$ & & & 120 \\
\hline & $1-8$ & & & $\mathbf{M}$ & & $117-125$ \\
\hline & 8 & & & $\mathbf{M}$ & & 120 \\
\hline \multirow[t]{2}{*}{ R53 } & Baseline & A & $\mathrm{T}$ & M & & 176 \\
\hline & 1 & & & $\mathbf{T}$ & & 158 \\
\hline \multirow[t]{3}{*}{ R54 } & Baseline & A & $\mathrm{M}, \mathrm{T}$ & & & 106 \\
\hline & $1-10$ & & & $\mathbf{T}$ & & $84-105$ \\
\hline & 10 & & $T$ & & & 93 \\
\hline \multirow[t]{3}{*}{ R62 } & Baseline & $\mathrm{A}, \mathrm{M}, \mathrm{T}$ & & & & 110 \\
\hline & $1-12$ & & $\mathbf{M}, \mathbf{T}$ & & & $81-110$ \\
\hline & 12 & & $\mathbf{M}, \mathbf{T}$ & & & 81 \\
\hline \multirow[t]{3}{*}{ R65 } & Baseline & A & $\mathrm{T}$ & M & & 117 \\
\hline & $1-4$ & & & $\mathbf{T}$ & & $120-130$ \\
\hline & 4 & & & $\mathbf{T}$ & & 120 \\
\hline
\end{tabular}

Italics decreased by 1 grade; bold increased by 1 grade; bold italics increased by 2 grades 
collect sufficient data to prove that the chosen therapeutic window was safe. We combined imaging assessments such as CT scans every 6 months for aneurysm evaluation, and echocardiography/Doppler every 2 months for valve formation, with plasma/serum cardiac risk markers.

Echocardiography/color Spectral Doppler was used to monitor possible structural and functional changes of the heart valves [17]. Because TGF- $\beta$ signaling and serotonin up-regulation in valvular toxicities have been associated, we used echocardiography/color and Spectral Doppler monitoring because it had been useful in identifying the serotonin-induced valve changes [25], in addition to monitoring potential toxicity to myocardial ventricular function. Alternatively, we considered the use of MRI [26], but decided against it because of the patient population and the need to compare results from various study sites. However, echocardiography/Doppler requires that patients are appropriately positioned and cooperative with the examination. In patients with end-of-life conditions, this may sometimes cause compliance issues; hence, the quality of the images can be sub-optimal. Images were generally of good quality, judged both by local review and by the central lab over read. Dual reading is advantageous in a multi-site study, by providing a local review for immediate patient safety, and a central review for consistent quantitation. A disadvantage for the central reviewer is the lack of important clinical information that generally helps in assessing the significance of abnormalities. For example, approximately $70 \%$ of the patients had minimal or small pericardial effusions per central review, deemed medically insignificant by the local cardiologist.

Biomarkers such as BNP and troponin I allowed more frequent monitoring than echocardiography/Doppler. They are used during chemotherapy to detect potential cardiac toxicities [27]. Hence, there is a good understanding on their levels in cancer patients. We observed that none of the patients had an increase of troponin I above $1.0 \mu \mathrm{g} / \mathrm{L}$. There were some patients who had a slight elevation of about $0.6 \mu \mathrm{g} / \mathrm{L}$ at the start of the trial and also occasionally during the treatment. However, this either did not increase or returned to norm values. This observation is consistent with other tumor types [28] and the slight increases in troponin I are seen in inflammatory conditions [29]. Recent guidelines provide recommendations on the interpretation of troponin elevations in different diseases [30]. The BNP values after age adjustment were generally within the norm values prior to the treatment and in most patients remained unchanged or even decreased. Serial BNP and troponin I levels supported the echocardiography/Doppler findings as previously described in patients with heart failure [31]. The use of hs-CRP was intended to detect inflammatory conditions that may have been induced by blocking the TGF- $\beta$ secretion. In toxicology studies of the rat with LY2157299, aneurysms were associated with inflammatory cell infiltrates. Hence, the hs-CRP was used as a possible early detection signal [32]. Except for occasional increases in some patients that were associated with infection, the hsCRP did not increase over time. The regular assessment of cystatin $\mathrm{C}$ was implemented as a potential marker for early detection in aneurysms because its reduction over time is associated with abdominal aneurysms [18]. The cystatin C levels were unchanged throughout the treatment with a few reductions in patients treated with LY2157299. In some patients with low pre-treatment levels, there were occasional reductions. However, in such patients or all other patients, the CT scans did not detect aneurysms in the thoracic aorta.

Although LY2157299 treatment was not associated with changes in the HERG-assay or in ECG evaluations in animals, we used ECG as an additional measure for cardiac safety. In general, about half of the patients had an abnormal ECG at baseline that did not change during treatment. This proportion of abnormal baseline ECGs is expected in a sample of adult patients in a clinical trial. In about one-third of the patients, the ECG readings changed from normal to abnormal. The frequencies of patients with a QTc increase of more than $30 \mathrm{~ms}$ were about $20 \%$; no patient had a prolongation of more than $60 \mathrm{~ms}$. After excluding influence factors such as co-medications with known QTc prolongation and considering the comorbidities of patients, there was no indication that LY2157299 induced QTc prolongation.

During treatment with LY2157299, the cardiac health of the glioma patients was unremarkable; LVEF remained unchanged and the blood pressure remained stable. The cardiac medication remained unaltered and patients did not require additional heart medication during the trial. This is also reflected in the serious adverse event/AE reports; no cardiac toxicities were reported. The case of one ischemic event happened after the patient had undergone a reresection of his tumor and thus was attributed to the surgery. Pulmonary embolism and dyspnea were considered to be associated with the disease as previously reported [33].

As part of the cardiovascular monitoring, all patients had to report the intake of LY2157299 in relationship to food. Because of the stringent administration requirements, patients administered LY2157299 early in the morning $(8: 00 \pm 1 \mathrm{~h})$ and early evening $(18: 00 \pm 1 \mathrm{~h})$. Because of this stringent administration schedule, diurnal fluctuations in cardiac monitoring were assessed and not observed.

An additional benefit of the comprehensive cardiovascular evaluation in this study is to confirm the stability of cardiac function, biomarkers and ECG parameters in sample of very ill cancer patients. Future studies of other cancer therapies can benchmark against these findings, allowing development teams to better determine whether 
an observed deterioration of cardiac function is due to drug or to the natural history of a late stage cancer.

Based on the lack of any medically significant cardiac events during the administration of LY2157299 either as a short-term or long-term treatment (including in patients treated over 3 years), either the therapeutic window was accurately predicted by the PK/PD model or the preclinical data in rats and dogs were not as predictive. Recently, studies were published that suggest TGF- $\beta$ is regulated differently in inbred rats, some of which are used in the preclinical assessment of toxicity risk [34]. Furthermore, if shear/stress is a key inducer for TGF- $\beta$ signaling [35], a block of this pathway may be resulting in more evident toxicity in species where the intravascular pressure is higher than in humans.

Acknowledgments This study was sponsored by Eli Lilly and Company, IN, USA. The authors want to thank Biomedical Systems (St. Louis, MO, USA), in particular Beth Gregory, for conducting the central review of all echocardiography/Doppler data. The sponsor also acknowledges the contribution of Quintiles and ICON staff to the implementation and the execution of this study. The sponsor thanks Kriss Harris for the statistical contribution to the present study. The authors thank Durisala Desaiah, PhD, Eli Lilly and Company, for the assistance with medical writing of this disclosure.

Conflict of interest Dr. Kovacs consults for Biomedical Systems, Cook, Eli Lilly, Euthymics, Intercept and Theravance; Drs. Azaro, Carducci, Corretti, Dolan, Fernández, Maldonado, Romero and Sepulveda-Sánchez have no conflict of interest. Dr. Baselga has received fees as consultant with Eli Lilly and Company. Drs. Lahn and Pillay are employees of Eli Lilly and Company, Indianapolis, IN, USA. Ms. Cleverly and Dr. Gueorguieva are employees of Eli Lilly and Company, Erl Wood, UK.

Open Access This article is distributed under the terms of the Creative Commons Attribution License which permits any use, distribution, and reproduction in any medium, provided the original author(s) and the source are credited.

\section{References}

1. Azhar, M., Schultz Jel, J., Grupp, I., Dorn, G. W., 2nd, Meneton, P., Molin, D. G., et al. (2003). Transforming growth factor beta in cardiovascular development and function. Cytokine \& Growth Factor Reviews, 14, 391-407.

2. Doetschman, T., Barnett, J. V., Runyan, R. B., Camenisch, T. D., Heimark, R. L., Granzier, H. L., et al. (2012). Transforming growth factor beta signaling in adult cardiovascular diseases and repair. Cell and Tissue Research, 347, 203-223.

3. Sridurongrit, S., Larsson, J., Schwartz, R., Ruiz-Lozano, P., \& Kaartinen, V. (2008). Signaling via the Tgf-beta type I receptor Alk5 in heart development. Developmental Biology, 322, 208-218.

4. Roberts, A. B., Anzano, M. A., Lamb, L. C., Smith, J. M., \& Sporn, M. B. (1981). New class of transforming growth factors potentiated by epidermal growth factor: Isolation from non-neoplastic tissues. Proceedings of the National Academy of Sciences of the United States of America, 78, 5339-5343.

5. Euler-Taimor, G., \& Heger, J. (2006). The complex pattern of SMAD signaling in the cardiovascular system. Cardiovascular Research, 69, 15-25.
6. Bujak, M., \& Frangogiannis, N. G. (2007). The role of TGF-beta signaling in myocardial infarction and cardiac remodeling. Cardiovascular Research, 74, 184-195.

7. de Oliveira, F. L., Araujo-Jorge, T. C., de Souza, E. M., de Oliveira, G. M., Degrave, W. M., Feige, J. J., et al. (2012). Oral administration of GW788388, an inhibitor of transforming growth factor beta signaling, prevents heart fibrosis in Chagas disease. PLoS Neglected Tropical Diseases, 6, e1696.

8. Grainger, D. J. (2007). TGF-beta and atherosclerosis in man. Cardiovascular Research, 74, 213-222.

9. Topper, J. N., Cai, J., Qiu, Y., Anderson, K. R., Xu, Y. Y., Deeds, J. D., et al. (1997). Vascular MADs: Two novel MAD-related genes selectively inducible by flow in human vascular endothelium. Proceedings of the National Academy of Sciences of the United States of America, 94, 9314-9319.

10. Jones, J. A., Spinale, F. G., \& Ikonomidis, J. S. (2009). Transforming growth factor-beta signaling in thoracic aortic aneurysm development: A paradox in pathogenesis. Journal of Vascular Research, 46, 119-137.

11. Van Laer, L., Dietz, H., \& Loeys, B. (2014). Loeys-Dietz syndrome. Advances in Experimental Medicine and Biology, 802, 95-105.

12. Anderton, M. J., Mellor, H. R., Bell, A., Sadler, C., Pass, M., Powell, S., et al. (2011). Induction of heart valve lesions by small-molecule ALK5 inhibitors. Toxicologic Pathology, 39, 916-924.

13. Rodon, J., Carducci, M. A., Sepúlveda, J. M., Azaro, A., Calvo, E., Seoane, J., et al. (2013). Integrated data review of the first-inhuman dose (FHD) study evaluating safety, pharmacokinetics $(P K)$, and pharmacodynamics $(P D)$ of the oral transforming growth factor-beta $(T G F-\beta)$ receptor $I$ kinase inhibitor, LY2157299 monohydrate (LY). Abstract number 2016, in annual meeting (oncology, A.S.o.C., Ed.), Chicago.

14. Gueorguieva, I., Cleverly, A. L., Stauber, A., Pillay, N. S., Rodon, J. A., Miles, C. P., et al. (2014). Defining a therapeutic window for the novel TGF- $\beta$ inhibitor LY2157299 monohydrate based on a pharmacokinetic/pharmacodynamic model. British Journal of Clinical Pharmacology, 77, 796-807.

15. Macdonald, D. R., Cascino, T. L., Schold, S. C., Jr, \& Cairncross, J. G. (1990). Response criteria for phase II studies of supratentorial malignant glioma. Journal of Clinical Oncology, 8, $1277-1280$.

16. Morganroth, J., Brozovich, F. V., McDonald, J. T., \& Jacobs, R. A. (1991). Variability of the QT measurement in healthy men, with implications for selection of an abnormal QT value to predict drug toxicity and proarrhythmia. The American Journal of Cardiology, 67, 774-776.

17. Zoghbi, W. A., Enriquez-Sarano, M., Foster, E., Grayburn, P. A., Kraft, C. D., Levine, R. A., et al. (2003). Recommendations for evaluation of the severity of native valvular regurgitation with two-dimensional and Doppler echocardiography. Journal of the American Society of Echocardiography, 16, 777-802.

18. Lindholt, J. S., Erlandsen, E. J., \& Henneberg, E. W. (2001). Cystatin $\mathrm{C}$ deficiency is associated with the progression of small abdominal aortic aneurysms. The British Journal of Surgery, 88, 1472-1475.

19. Members, W. C., Hiratzka, L. F., Bakris, G. L., Beckman, J. A., Bersin, R. M., Carr, V. F., et al. (2010). 2010 ACCF/AHA/AATS/ ACR/ASA/SCA/SCAI/SIR/STS/SVM guidelines for the diagnosis and management of patients with thoracic aortic disease: Executive summary: A report of the American College of Cardiology Foundation/American Heart Association Task Force on Practice Guidelines, American Association for Thoracic Surgery, American College of Radiology, American Stroke Association, Society of Cardiovascular Anesthesiologists, Society for Cardiovascular Angiography and Interventions, Society of 
Interventional Radiology, Society of Thoracic Surgeons, and Society for Vascular Medicine. Circulation, 121, 1544-1579.

20. Benvenuto, G. M., Ometto, R., Fontanelli, A., Fortunato, A., Ruffini, P. A., Fosser, V., \& Morandi, P. (2003). Chemotherapyrelated cardiotoxicity: New diagnostic and preventive strategies. Italian Heart Journal: Official Journal of the Italian Federation of Cardiology, 4, 655-667.

21. Witteles, R. M., \& Telli, M. (2012). Underestimating cardiac toxicity in cancer trials: Lessons learned? Journal of Clinical Oncology, 30, 1916-1918.

22. Lipshultz, S. E., Landy, D. C., Lopez-Mitnik, G., Lipsitz, S. R., Hinkle, A. S., Constine, L. S., et al. (2012). Cardiovascular status of childhood cancer survivors exposed and unexposed to cardiotoxic therapy. Journal of Clinical Oncology, 30, 1050-1057.

23. Choueiri, T. K., Mayer, E. L., Je, Y., Rosenberg, J. E., Nguyen, P. L., Azzi, G. R., et al. (2011). Congestive heart failure risk in patients with breast cancer treated with bevacizumab. Journal of Clinical Oncology, 29, 632-638.

24. Ryberg, M., Nielsen, D., Skovsgaard, T., Hansen, J., Jensen, B. V., \& Dombernowsky, P. (1998). Epirubicin cardiotoxicity: An analysis of 469 patients with metastatic breast cancer. Journal of Clinical Oncology, 16, 3502-3508.

25. Xu, J., Jian, B., Chu, R., Lu, Z., Li, Q., Dunlop, J., et al. (2002). Serotonin mechanisms in heart valve disease II: The 5-HT2 receptor and its signaling pathway in aortic valve interstitial cells. The American Journal of Pathology, 161, 2209-2218.

26. Mor-Avi, V., Sugeng, L., Weinert, L., MacEneaney, P., Caiani, E. G., Koch, R., et al. (2004). Fast measurement of left ventricular mass with real-time three-dimensional echocardiography: Comparison with magnetic resonance imaging. Circulation, 110, $1814-1818$

27. Colombo, A., Sandri, M. T., Salvatici, M., Cipolla, C. M., \& Cardinale, D. (2014). Cardiac complications of chemotherapy: Role of biomarkers. Current Treatment Options in Cardiovascular Medicine, 16, 313.
28. Goel, S., \& Beith, J. M. (2011). Troponin I as a predictor for trastuzumab-related cardiotoxicity: Current data do not provide mechanistic insights or allow for incorporation into clinical practice. Journal of Clinical Oncology, 29, e175-e176.

29. van Bockel, E. A., Tulleken, J. E., Muller Kobold, A. C., Ligtenberg, J. J., van der Werf, T. S., Spanjersberg, R., \& Zijlstra, J. G. (2003). Cardiac troponin I release and cytokine response during experimental human endotoxaemia. Intensive Care Medicine, 29, 1598-1600.

30. Newby, L. K., Jesse, R. L., Babb, J. D., Christenson, R. H., De Fer, T. M., Diamond, G. A., et al. (2012). ACCF 2012 expert consensus document on practical clinical considerations in the interpretation of troponin elevations: A report of the American College of Cardiology Foundation task force on Clinical Expert Consensus Documents. Journal of the American College of Cardiology, 60, 2427-2463.

31. Sanderson, J. E. (2004). BNP or echocardiography for monitoring heart failure? European Heart Journal, 25, 1763-1764.

32. Onitilo, A. A., Engel, J. M., Stankowski, R. V., Liang, H., Berg, R. L., \& Doi, S. A. (2012). High-sensitivity C-reactive protein (hs-CRP) as a biomarker for trastuzumab-induced cardiotoxicity in HER2-positive early-stage breast cancer: A pilot study. Breast Cancer Research and Treatment, 134, 291-298.

33. Semrad, T. J., O’Donnell, R., Wun, T., Chew, H., Harvey, D., Zhou, H., \& White, R. H. (2007). Epidemiology of venous thromboembolism in 9489 patients with malignant glioma. Journal of Neurosurgery, 106, 601-608.

34. Behmoaras, J., Osborne-Pellegrin, M., Gauguier, D., \& Jacob, M. P. (2005). Characteristics of the aortic elastic network and related phenotypes in seven inbred rat strains. American Journal of Physiology Heart and Circulatory Physiology, 288, H769-H777.

35. Walshe, T. E., dela Paz, N. G., \& D'Amore, P. A. (2013). The role of shear-induced transforming growth factor-beta signaling in the endothelium. Arteriosclerosis, Thrombosis, and Vascular Biology, 33, 2608-2617. 